\title{
Goal Setting to Increase Student Academic Performance
}

Ronnie Dotson, Superintendent

Carter County Schools, Kentucky

High-stakes accountability has teachers and administrators across the nation searching for proven strategies to ensure continual improvement. Additionally, establishing processes that promote shared leadership and responsibility for student achievement is of great interest to educators. Furthermore, motivating students to perform at high levels has become increasingly challenging. Jenkins (1994) advocates that many students' greatest problems in school are related to irresponsibility, not inability. Hwang (1995) reports that the apathetic attitude of American students is profound. The effects of this complacent outlook and lack of motivation is far reaching and necessitates a new direction in order for schools to reach their goals. For the schools in Carter County, Kentucky, a rural district of approximately 5,000 students, goal setting has proven to be the answer.

Over the past two years, the teachers and students in Carter County have been utilizing goal setting. As a result, the district has shown tremendous growth on not only state assessments, but also on local assessments. Additionally, the number of students meeting benchmarks for college and career readiness has increased significantly. The strategy has provided students and teachers a focus that has enhanced student performance.

\section{Goal Setting Defined}

Goal setting as defined in Classroom Instruction that Works, is the process of establishing a direction for learning (Marzano, Pickering, \& Pollock, 2001). Schunk (2009) clarifies that while goal setting can lead to student motivation and higher academic achievement, simply stating a goal does not automatically benefit students. However, if implemented correctly, goal setting has the potential to positively impact learning.

\section{Methodology}

To measure the impact of goal setting on reading achievement, student performance on the reading section of the state assessment were analyzed when students were in fourth and fifth grades. Data from the 2014 state reading assessment, when the selected students were in fourth grade and did not participate in goal setting, were compared with data from the 2015 state reading assessment, when these same students were in fifth grade and participated in goal setting. McNemar's Change Test analysis was used to determine if a significant difference existed between the reading growth achieved in fourth grade compared to reading growth achieved in fifth grade.

\section{Results}

Of the 328 students participating in the study, $69 \%$ made adequate growth after goal setting utilization as compared to only $60 \%$ prior to the implementation of goal setting. Specifically, McNemar's Test results indicated that a significant difference existed in the reading growth performance when comparing the reading growth for the two year period $\left(x^{2}=9.986, d f=1, p\right.$ $=.0016)$. In $2014,60.4 \%$ of the students were classified as making adequate growth, whereas $68.6 \%$ received the designation in 2015 (Dotson, 2015).

\section{Discussion}

\section{Goal Setting in Carter County}

Before leading students in the process of writing effective goals, it is imperative that teachers are knowledgeable of the process. Like students, teachers must experience the different goal types, components, and steps required to successfully mentor others toward reaching individual goals. Start by asking teachers to choose a trusted colleague to serve as a learning partner. Letting adults decide on their partner will make teachers more comfortable during the learning process. Partners will work together during the orien- 
tation phase to coach each other through the different steps of goal setting. Then, in the same manner that we explicitly teach children by connecting new learning with prior knowledge, begin teachers' practice of goal setting by choosing a topic that they are familiar with such as weight loss. Allow teachers to record their current weight and their desired weight on paper. Next, discuss the different types of activities that they can do to assist them in reaching their established ideal weight. Then, ask participants to determine a timeline for achieving their goal. It is important to realize that some teachers will have a much larger range between their current weight and their desired weight, pushing the goal date ahead for some people. Finally, establish dates for progress monitoring so that the teacher partners can discuss progress toward reaching the goal and revisions of activities if necessary. This practice will enable teachers to better relate to the concerns and possible misconceptions that students will have when they begin the process.

Providing teachers opportunities to become proficient in each step of goal setting before introducing the strategy to students provides a common language and a uniform process throughout the school. Students should be taught to record their goals on paper so that they can refer back to it throughout the learning process. The documentation should include a place for the specific goal, anticipated date for accomplishment, activities that will be implemented in an effort to achieve the goal, progress monitoring notes, and a place for both student and teacher signatures. Having students sign the goal form increases the level of accountability and further confirms the expectation that the teacher has for the student.

\section{Four Steps to Successful Academic Goal Implemen- tation}

1. Set goals that are specific, measureable, attainable, realistic, and time sensitive. In order for students to view goals as meaningful, they must have a clear understanding of what specific target(s) they are aspiring to accomplish (Doran, 1981). There are a couple of options for developing effective student growth goals. First, goals may be set for individual learning targets as in the following example: "By May 15, 2015, I will identify the three branches of government and explain the function of each with 100\% accuracy." This goal contains the five critical elements of being specific, measurable, attainable, relevant, and time sensitive. A second option for setting student academic growth goals is to focus on an entire exam. Unit tests, benchmark assessments, and state assessments are some possibilities for which goals may be set as in the following example: "By May 30, 2015, I will increase my ACT composite score from 22 to 24". This goal also contains the critical elements of being specific, measureable, attainable, relevant, and time sensitive.

2. Develop a plan of action. As stated earlier, simply writing down a goal does not impact student learning. It is the activities that the student will participate in during the learning process that have the potential to positively influence student achievement. In collaboration with the teacher, the student will need to brainstorm different possibilities beyond core instruction that could increase achievement. I do not recommend writing generic actions such as paying better attention in class, trying harder, or turning in all assignments; these are things that should be part of the standard expectations for all students. Activities should be meaningful and provide learning opportunities that will enhance the student's knowledge and understanding in the specified area. One example to consider is encouraging the student to spend a minimum of one hour for two evenings per week on a research-based computer program designed to provide enrichment in the specific area of concentration. Another idea is to have the student commit to afterschool tutoring or enrichment for a specified number of times per week. It's important to consider when developing activities to ensure that they are specific to the child's goal and that there is a means of accountability. If the accountability piece is missing from the activity, the likelihood of the student actually completing the activity decreases. Adding accountability to some traditional activities takes a little creativity, but it is worth the effort. Take the following example: A child sets a goal of scoring $95 \%$ on the upcoming social studies exam and decides on a plan of action that consists of studying for 30 minutes each day. I think we can all agree that studying for 30 minutes each day for the test would be a great activity for any student. However, there is the possibility that the child will not follow through with the commitment because of the lack of accountability. Having a parent or guardian sign a student-generated form each evening verifying the amount of time spent studying adds accountability, increasing the probability that the activity will take place.

3. Monitor progress frequently. The third step in student goal implementation is arguably the most important. Monitoring the impact that the planned activities have on student success is imperative. This step requires the teacher to monitor the progress that the student is making toward reaching established goals. This process further allows the teacher to eval- 
uate their instructional practices to determine effectiveness. Additionally, as student ownership is a critical piece in goal setting, progress monitoring provides a system to ensure that students value and own their learning. Progress monitoring allows for this structure by immersing students in the implementation of a self-developed needs-based action plan that is evaluated systematically. A simple approach to monitor a student goal is to create a trajectory with small interim goals along the way. For example, if a student is currently reading 60 words per minute and has set a goal to read 100 words per minute, establishing target points along the way will help to monitor progress and provide motivational support. If after one month of goal implementation the student increases fluency to 80 words per minute, the student and teacher will know that the specific strategies are working. In addition, realizing that their efforts are producing results will motivate students and teachers to attain even higher levels of achievement.

4. Celebrate successes-even the small ones. We have all heard the age-old adage that "success breeds success," and as it turns out, there is validity in the proverb (Rijt, Kang, Restivo, \& Patil, 2014). As students realize success in reaching their goals, it is important that accomplishments are celebrated. Recognizing the efforts of students will motivate them to strive for greater success as well as encourage teachers in their quest to help all students succeed. I recently visited a local high school where students were taking a placement assessment that measured their abilities in math. If students reached an established benchmark on the assessment, they would not be required to take a remedial math course in college. The students shared with me some of the rigorous work they had completed in an effort to prepare for the assessment. Goal documentation indicated intensive work that had been completed for several weeks including attending tutoring sessions after school. It was obvious that these students were committed to their goal of a successful outcome on the assessment. The assessment was computer based and results were immediately revealed to students. Most of the students were successful and met the required benchmark. The celebration for these students began immediately with everything from tears to high fives. Three students, however, were not celebrating; the students felt defeated as they had not reached the required benchmark. Realizing the importance of celebrating even the small things, the teacher serving as the mentor for the three students approached the students with a smile telling them of the great progress that had made. She pointed out the different activities they had been successful at completing and how much growth they had shown. When she finished with her talk, the frowns turned into smiles and the students' defeated attitudes turned into determination. While these students did not recognize complete success of their goal, they had improved, and that was reason to celebrate. To further emphasize the spirt of celebration, all students were individually recognized for their determination. While these students did not recognize complete success of their goal, they had improved, and that was reason to celebrate. To further emphasize the spirt of celebration, all students were individually recognized for completing the activities outlined in their goal documentation during a schoolwide assembly. This recognition ceremony, which recognized effort, reinforced the importance of trying your best even if the desired outcome is not fully realized.

The power of goal setting has been studied for many years. Setting goals keeps students focused on desired outcomes and provides a clear direction for success. The key to establishing goals that produce results is making them specific, measureable, attainable, relevant, and time sensitive. Furthermore, goals must be supported by a specific plan of action that outlines the steps to be taken to maximize success. Monitoring the progress of the plan ensures that activities being utilized are producing the desired outcomes. Lastly, celebrating the progress made by students reinforces the importance of effort and recognizes improvements.

\section{References}

Dotson, R. (2015). Does goal setting with elementary students impact reading growth? (Doctoral dissertation). Retrieved from ProQuest Dissertations Publishing. (Accession No. 10019493).

Doran. (1981). There's a S.M.A.R.T. way to write management's goals and objectives. Management Review, 70(11), 35-36.

Hwang, Y. (1995). Student apathy, lack of self-responsibility and false self-esteem are failing American schools. Education, 115(4), 484-490.

Jenkins, D. (1994). An eight-step plan for teaching responsibility. The Clearing House: A Journal of Educational Strategies, Issues and Ideas, 67(5), 269-270.

Marzano, R., Pickering, D., \& Pollock, J. (2001). Classroom instruction that works. Association for Supervision and Curriculum Development. Alexandria, VA

Rijt, A., Kang, S., Restivo, M., \& Patil, A. (2014). Field experiments of success breeds success dynamics. Proceedings of the National Academy of Sciences, 111(9), 6934-6939.

Schunk, D. (2009). Goal setting. Retrieved from education.com: http://www.education.com/reference/article/goalsetting/ 